\title{
Removal of Toluene by Adsorption/Desorption Using Ultra-stable Y Zeolite
}

\author{
Lei Xu ${ }^{1,2,3} \cdot$ Yonghong $\mathrm{Li}^{1,2,3} \cdot$ Jiang $\mathrm{Zhu}^{1,2,3} \cdot$ Zhiyuan Liu ${ }^{1,2,3}$
}

Received: 6 September 2018 / Revised: 14 October 2018 / Accepted: 14 December 2018 / Published online: 21 January 2019

(c) The Author(s) 2019

\begin{abstract}
The adsorption performance of toluene on ultra-stable Y zeolite (USY) was studied via dynamic adsorption. The effects of bed temperature, initial concentration, and feed flow rate on adsorption were investigated. The Yoon-Nelson model was used to fit the toluene breakthrough curves. The length of mass transfer zone was calculated based on breakthrough curves. The Langmuir-Freundlich model fit the adsorption isotherms of toluene on USY, which indicated that the surface of USY was heterogeneous. The adsorption isosteric heat calculated from adsorption isotherms ranged from 54.3 to $69.8 \mathrm{~kJ} / \mathrm{mol}$, indicating physical adsorption. The combined technique of temperature swing adsorption with vacuum swing adsorption (TVSA) exhibited excellent desorption performance, which was attributed to the low desorption activation energy. Under optimized TVSA conditions, the desorption rate of toluene reached $90.6 \%$ within $10 \mathrm{~min}$. The long-term cyclic utilization results indicated that the adsorption capacity of USY was stable.
\end{abstract}

Keywords Adsorption · Desorption $\cdot$ USY $\cdot$ Toluene $\cdot$ Heavy VOC

\section{List of Symbols}

$q \quad$ Adsorbed amount of toluene at time $t(\mathrm{~g} / \mathrm{g})$

$q_{\mathrm{e}} \quad$ Adsorbed amount of toluene at saturation $(\mathrm{g} / \mathrm{g})$

$q_{\mathrm{m}} \quad$ Maximum theoretical adsorption capacity $(\mathrm{g} / \mathrm{g})$

$Q \quad$ Adsorbed amount of toluene ( $\mathrm{mmol} / \mathrm{g}$ )

$F \quad$ Feed flow rate of toluene vapor $(\mathrm{mL} / \mathrm{min})$

$W \quad$ Weight of adsorbent (g)

$C_{0} \quad$ Initial concentration of toluene $\left(\mathrm{mg} / \mathrm{m}^{3}\right)$

$C \quad$ Outlet concentration of toluene $\left(\mathrm{mg} / \mathrm{m}^{3}\right)$

$d_{\mathrm{r}} \quad$ Desorption rate of toluene (\%)

$m \quad$ Mass of fresh adsorption tube $(\mathrm{g})$

$m_{\mathrm{a}} \quad$ Mass of adsorption tube before desorption (g)

$m_{\mathrm{d}} \quad$ Mass of adsorption tube after desorption $(\mathrm{g})$

$k \quad$ Rate constant of Yoon-Nelson model

$k_{0} \quad$ Pseudo-zero-order rate constant $(\mathrm{g} / \mathrm{min})$

$k_{1} \quad$ Pseudo-first-order rate constant $\left(\mathrm{min}^{-1}\right)$

Yonghong Li

yhli@tju.edu.cn

1 Key Lab for Green Chemical Technology of Ministry of Education, School of Chemical Engineering and Technology, Tianjin University, Tianjin 300350, China

2 National Engineering Research Center for Distillation Technology, Tianjin 300350, China

3 Collaborative Innovation Center of Chemical Science and Engineering, Tianjin 300350, China $t \quad$ Adsorption time (min)

$t_{0.5} \quad$ Time corresponding to $C / C_{0}=0.5(\mathrm{~min})$

$t_{0.05}$ Time corresponding to $C / C_{0}=0.05$ (min)

$t_{0.95}$ Time corresponding to $C / C_{0}=0.95(\mathrm{~min})$

$H_{\mathrm{MTZ}}$ Length of the mass transfer zone $(\mathrm{cm})$

$H \quad$ Length of the tubular adsorbent bed $(\mathrm{cm})$

$p \quad$ Toluene partial pressure $(\mathrm{Pa})$

$b \quad$ Affinity term at experimental condition

$1 / n \quad$ Exponent of Langmuir-Freundlich model

A Affinity coefficient

$\Delta H \quad$ Isosteric heat of adsorption $(\mathrm{kJ} / \mathrm{mol})$

$T \quad$ Adsorption temperature (K)

$R \quad$ Gas constant $\left(8.314 \mathrm{~J} \mathrm{~K}^{-1} \mathrm{~mol}^{-1}\right)$

$E_{\mathrm{d}} \quad$ Activation energy of desorption $(\mathrm{kJ} / \mathrm{mol})$

$\beta_{\mathrm{H}} \quad$ TPD heating rate $(\mathrm{K} / \mathrm{min})$

$T_{\mathrm{p}} \quad$ Temperature corresponding to desorption peak (K)

\section{Introduction}

Volatile organic compounds (VOCs) usually refer to organic compounds with boiling points within the range of $50-260{ }^{\circ} \mathrm{C}$ at atmospheric pressure [1]. These compounds include aromatics, aliphatics, aldehydes, ketones, and esters. Discharged VOCs can react with $\mathrm{NO}_{x}$ in the atmosphere to generate photochemical smog, which poses a serious threat 
to human health and the environment [2]. About 29.4 million tons of industrial VOC emissions were estimated to be discharged into the atmosphere in China in 2013 [3]. This large amount of VOC emissions has resulted in serious environmental issues. Hence, efforts must be made to reduce the emission of VOCs. Toluene is one of the main components of VOCs, and it widely exists in the printing, painting, semiconductor, and leather industries. In recent years, toluene has attracted increasing research attention [4-6].

Several techniques have been applied in controlling VOC emissions, including adsorption [7], absorption [8], photocatalysis [9], thermocatalysis [10], plasma catalytic oxidation [11], and biofiltration [12]. Among these methods, adsorption is an effective way to remove VOCs with low concentration and high velocity, because of its high efficiency and low cost [13]. The most commonly used adsorbent is activated carbon because of its large adsorption capacity. However, the regeneration of activated carbon is difficult because of its thermal and chemical instability [14]. Therefore, zeolites as adsorbents are becoming increasingly popular for their large surface area, high thermal and hydrothermal stability, adjustable hydrophobicity, auxiliary mesopore regeneration, and non-flammable characteristics $[15,16]$.

On the basis of the desorption methods, the adsorption are divided into temperature swing adsorption (TSA) and pressure swing adsorption (PSA). Given its short desorption time and low energy consumption, PSA or vacuum swing adsorption (VSA) has experienced rapid development. However, this method is commonly used for the treatment of light VOCs, like ethanol, acetone, and ethane [17-19]. For heavy VOCs (e.g., aromatics), the desorption rate is low using single VSA. Sui et al. [20] investigated the removal of $\mathrm{o}-\mathrm{xylene}$ using silica gel by VSA. They found that the maximum desorption rate of o-xylene is $58 \%$ via single VSA. Therefore, the combination of temperature swing adsorption and vacuum swing adsorption (TVSA) was proposed for the removal of heavy VOCs. TVSA was expected to lower the desorption temperature, enhance the desorption rate, and shorten the desorption time of heavy VOCs. Pak et al. [21] studied the adsorption and desorption of toluene using commercial activated carbons by TVSA. They reported a toluene desorption rate of $90 \%$ under the desorption conditions of $90{ }^{\circ} \mathrm{C}$ and $13 \mathrm{kPa}$. However, the desorption equilibrium time was as long as $150 \mathrm{~min}$, and the adsorption breakthrough time sharply decreased from $200 \mathrm{~min}$ to $80 \mathrm{~min}$ after five cycles. The poor stability and long desorption time limit the application of TVSA with activated carbon as adsorbent. Ultra-stable Y zeolite (USY) is an excellent adsorbent for heavy VOC because of its large specific surface area, suitable pore width and excellent thermal stability. However, few studies have been reported on TVSA with USY as adsorbent. The mechanism of VOC adsorption and desorption on USY remains unclear. This paper may provide guidance for the application of USY in treating emissions from the paint and printing industries, which involve large aromatic VOCs.

This work aimed to (1) test the effects of adsorption conditions, (2) analyze the dynamics and thermodynamics of adsorption and desorption, (3) reveal the superiority of TVSA and optimize the operational conditions of TVSA, and (4) determine the feasibility of the industrial application of TVSA in the removal of heavy VOCs.

\section{Material and Method}

\section{Materials}

USY ( $\mathrm{Si} / \mathrm{Al}=11,25,40)$ used in the experiments was purchased from Zibo Mengzhong Import and Export Trade Co., Ltd. (Shandong, China). The cation type of USY was hydrogen. Toluene $\left(\mathrm{C}_{7} \mathrm{H}_{8}>99.5 \%\right)$ was purchased from Tianjin Yuanli Chemical Co., Ltd. (Tianjin, China).

\section{Characterization of USY}

The nitrogen adsorption-desorption isotherms of USY were measured by Autosorb-iQ2-MP (Quantachrome, USA) at $77 \mathrm{~K}$. Before sorption measurement, the samples were outgassed at $573 \mathrm{~K}$ for $5 \mathrm{~h}$. The specific surface area and micropore volume were calculated by Brunauer-Emmett-Teller (BET) and t-plot models, respectively. The pore width distribution of USY was estimated by density functional theory.

Temperature programmed desorption (TPD) experiments were performed on self-built equipment, composed of a quartz reactor placed inside an electronic temperature programmed furnace and connected to a gas chromatograph with an FID detector. The toluene-laden USY ( $0.2 \mathrm{~g})$ was quickly packed in a quartz tube between two silica wool plugs. The nitrogen flow rate was $30 \mathrm{~mL} / \mathrm{min}$, and the heating rate varied from 3 to $15 \mathrm{~K} / \mathrm{min}$.

\section{Dynamic Adsorption and Desorption of Toluene}

The dynamic adsorption and desorption of toluene were carried out in the self-made experimental device (Fig. 1). Air flowed out from the cylinder and was split into three streams. One of the streams was used to generate toluene vapor, the other stream was used to generate moisture, and the third was used as dilute gas. By adjusting the flow rates of the three streams, toluene stream with a certain concentration and moisture was obtained. The toluene mixture was introduced to the adsorption tube (adsorbent mass $=0.5 \mathrm{~g}$, particle size $=40-60$ mesh, inner diameter $=5.5 \mathrm{~mm}$, and length $=5.89 \mathrm{~cm}$ ). The concentration of inlet and outlet stream was detected by a gas chromatograph (FULI 9790, China) with an FID detector. 


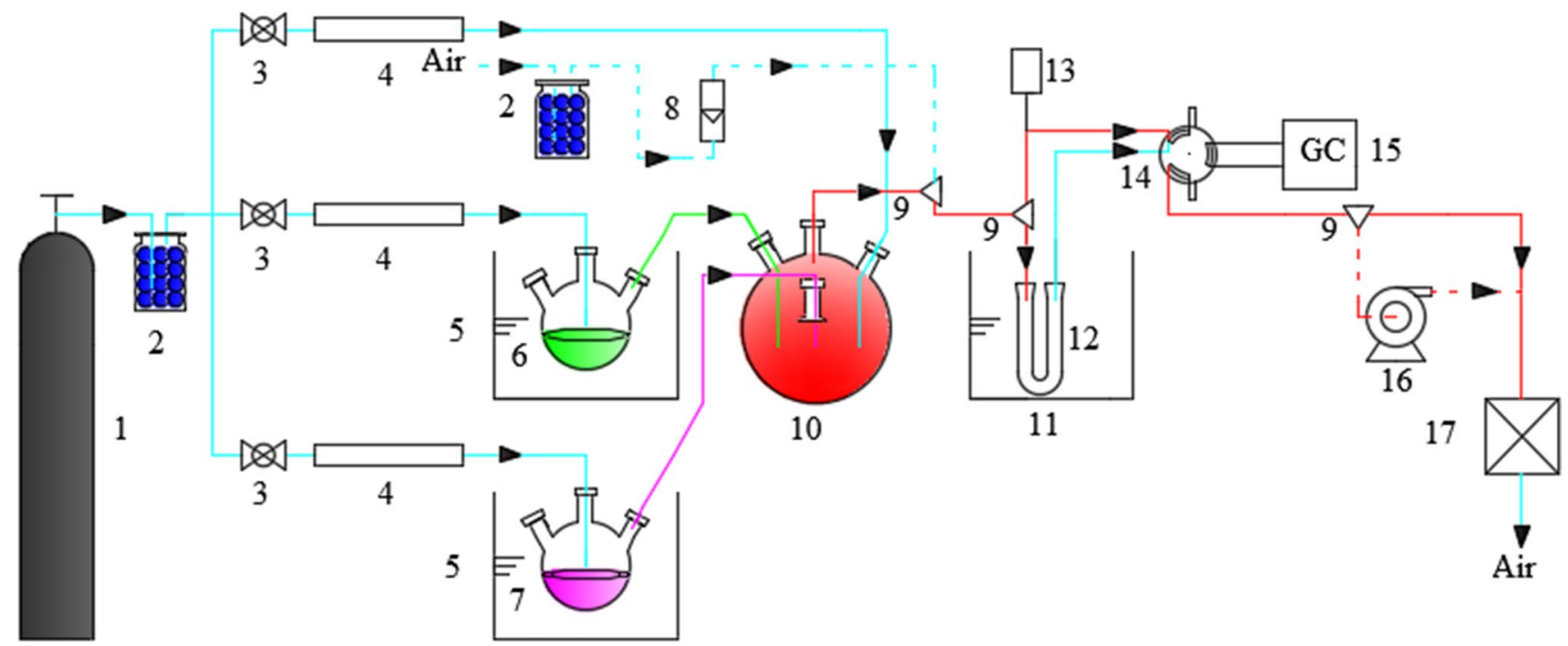

Fig. 1 Schematic flowchart of adsorption and desorption experiments. (1) air cylinder; (2) dryers; (3) ball values; (4) mass flow controllers; (5) water baths; (6) water stream generator; (7) toluene stream generator; (8) rotor flow meter; (9) three-way valves; (10)

The temperatures of the chromatographic column, injector, and detector were $150{ }^{\circ} \mathrm{C}, 170{ }^{\circ} \mathrm{C}$, and $180{ }^{\circ} \mathrm{C}$, respectively. When the toluene concentration in the outlet stream was constant and equal to that in the inlet stream, the adsorption tube was saturated by toluene.

When the adsorption process was completed, the adsorption tube was removed from the oil bath. The oil bath was heated to the desired desorption temperature, and the adsorption tube was placed into the oil bath. Finally, the valves were switched and connected to a vacuum pump for desorption. During desorption, a stream of purge air was introduced to the adsorption tube. The chromatographic conditions for the detection of desorption gas were similar to those for adsorption gas.

\section{Principle}

\section{Adsorption Amount and Desorption Rate}

The amount of toluene adsorbed was calculated by the following formula:

$q=\frac{F \times 10^{-9}}{W}\left(C_{0} t-\int_{0}^{t} C(t) \mathrm{d} t\right)$

The desorption rate was measured by the gravimetric method and calculated by Eq. (2):

$d_{\mathrm{r}}=\frac{m_{\mathrm{a}}-m_{\mathrm{d}}}{m_{\mathrm{a}}-m} \times 100 \%$ stream mixture; (11) oil bath; (12) adsorption tube; (13) hygrothermograph; (14) six-port valve; (15) gas chromatograph; (16) vacuum pump; and (17) exhaust gas adsorption tank

\section{Yoon-Nelson Model}

The Yoon-Nelson model was used to simulate the breakthrough curves of toluene [22].

$\frac{C}{C_{0}}=\frac{1}{1+\exp \left[k\left(t_{0.5}-t\right)\right]}$

The length of mass transfer zone (MTZ) was calculated from breakthrough curves using the following equation [23]:

$H_{\mathrm{MTZ}}=H \times \frac{t_{0.5}-t_{0.05}}{t_{0.95}}$

\section{Adsorption Kinetic Model}

The pseudo-zero-order model is presented as

$\frac{\mathrm{d} q}{\mathrm{~d} t}=k_{0}$

The pseudo-first-order model is presented as [24]

$\frac{\mathrm{d} q}{\mathrm{~d} t}=k_{1} \times\left(q_{\mathrm{e}}-q\right)$

\section{Adsorption Isotherms}

The Langmuir adsorption isotherm describes homogeneous adsorption in which the adsorption enthalpy and activated energy are constant to each molecule (all sites show affinity to molecule) [25]. It is expressed as follows:

$q_{\mathrm{e}}=\frac{q_{\mathrm{m}} \times b \times p}{(1+b \times p)}$ 
The Freundlich adsorption isotherm describes multilayer adsorption, which is presented as [26].

$q_{\mathrm{e}}=A \times p^{\frac{1}{n}}$

The Langmuir-Freundlich adsorption isotherm was used to describe heterogeneous adsorption [27].

$q_{\mathrm{e}}=q_{\mathrm{m}} \times \frac{b \times p^{\frac{1}{n}}}{\left(1+b \times p^{\frac{1}{n}}\right)}$

The isosteric heat of adsorption was estimated by Clausius-Clapeyron equation [28].

$\frac{\Delta H}{R}=\left[\frac{\partial \ln (p)}{\partial(1 / T)}\right]_{Q}$

\section{Desorption Activation Energy}

The desorption activation energy was estimated by the modified Polanyi-Wigner equation using TPD [29].

$\ln \left(\frac{\beta_{\mathrm{H}}}{R T_{\mathrm{p}}^{2}}\right)=-\left(\frac{E_{\mathrm{d}}}{R T_{\mathrm{p}}}\right)-\ln \left(\frac{E_{\mathrm{d}}}{k_{0}}\right)$

\section{Results and Discussion}

\section{Characterization of Adsorbents}

Figure 2 illustrates the $\mathrm{N}_{2}$ adsorption-desorption isotherms and the pore width distribution of USY. The steep increase in adsorbed amounts of $\mathrm{N}_{2}$ was observed at low relative pressure $\left(p / p_{0}<0.05\right)$, which suggested the large micropore volume. The hysteresis loops $\left(p / p_{0}=0.45-0.95\right)$ indicated the mesopore volume. These phenomena suggested that USY possessed micro-mesopore structures, which are advantageous for both adsorption and desorption [30,31]. With the increase in $\mathrm{Si} / \mathrm{Al}$ ratios, the BET specific surface area and pore volume of USY initially increased and then decreased. The detailed parameters are shown in Table 1.

\section{Effect of Si/AI Ratios on Adsorption}

Figure 3 shows the breakthrough curves of toluene at different relative humidities. In Fig. 3a, the USYs with different $\mathrm{Si} / \mathrm{Al}$ ratios presented similar adsorption performance when toluene vapor lacked moisture. However, the USYs with different $\mathrm{Si} / \mathrm{Al}$ ratios showed a remarkable difference in adsorption at the relative humidity (RH) of 50\%, (Fig. 3b). The breakthrough time improved with the increase in $\mathrm{Si} /$
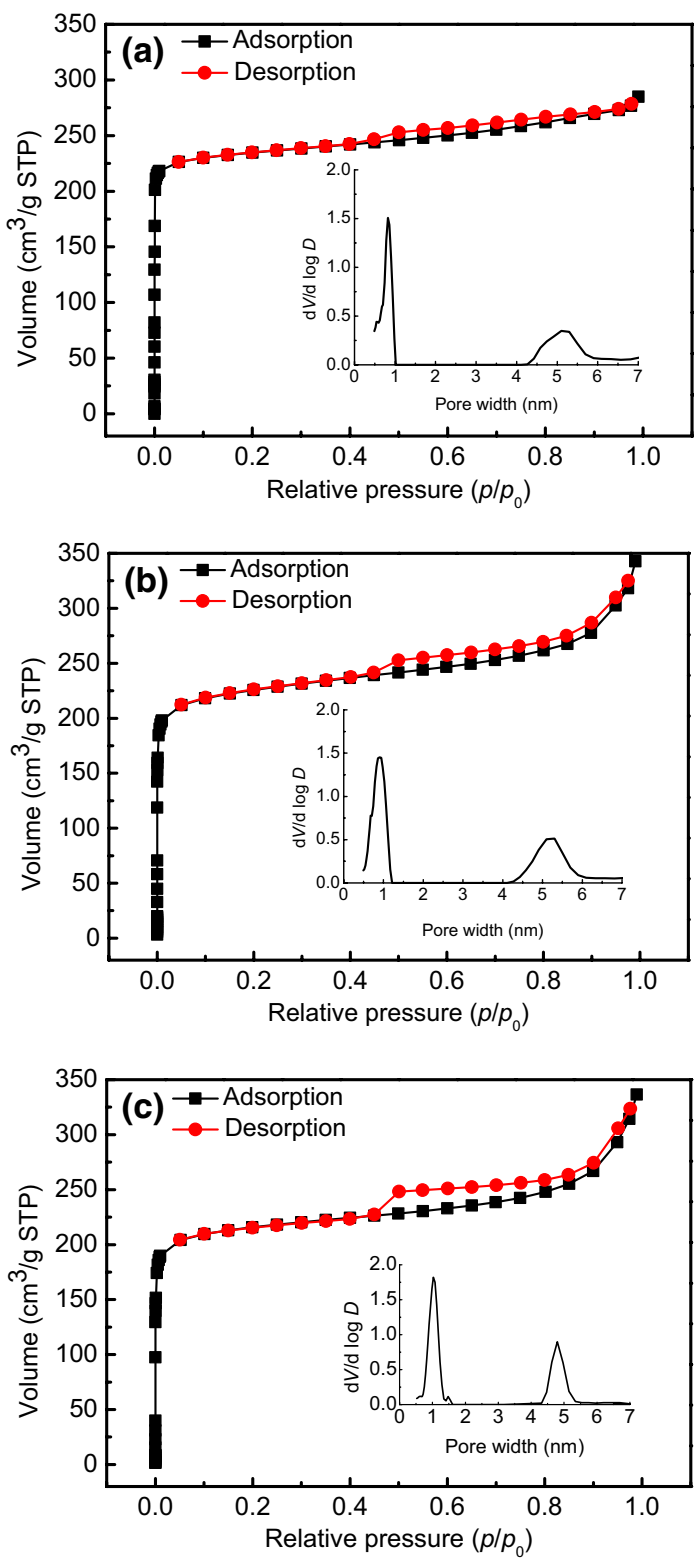

Fig. 2 Nitrogen adsorption-desorption isotherms and pore width distribution (insets) of USYs with different $\mathrm{Si} / \mathrm{Al}$ ratios: a $\mathrm{Si} / \mathrm{Al}=11 ; \mathbf{b}$ $\mathrm{Si} / \mathrm{Al}=25 ;$ c Si$/ \mathrm{Al}=40$

Table 1 Main characteristics of different USYs

\begin{tabular}{lllll}
\hline Adsorbent & $\begin{array}{l}\text { BET surface } \\
\text { area }\left(\mathrm{m}^{2} / \mathrm{g}\right)\end{array}$ & $\begin{array}{l}\text { Micropore } \\
\text { volume } \\
\left(\mathrm{cm}^{3} / \mathrm{g}\right)\end{array}$ & $\begin{array}{l}\text { External } \\
\text { volume } \\
\left(\mathrm{cm}^{3} / \mathrm{g}\right)\end{array}$ & $\begin{array}{l}\text { Total pore } \\
\text { volume } \\
\left(\mathrm{cm}^{3} / \mathrm{g}\right)\end{array}$ \\
\hline USY-11 & 748 & 0.284 & 0.124 & 0.408 \\
USY-25 & 881 & 0.315 & 0.150 & 0.465 \\
USY-40 & 848 & 0.303 & 0.141 & 0.444 \\
\hline
\end{tabular}



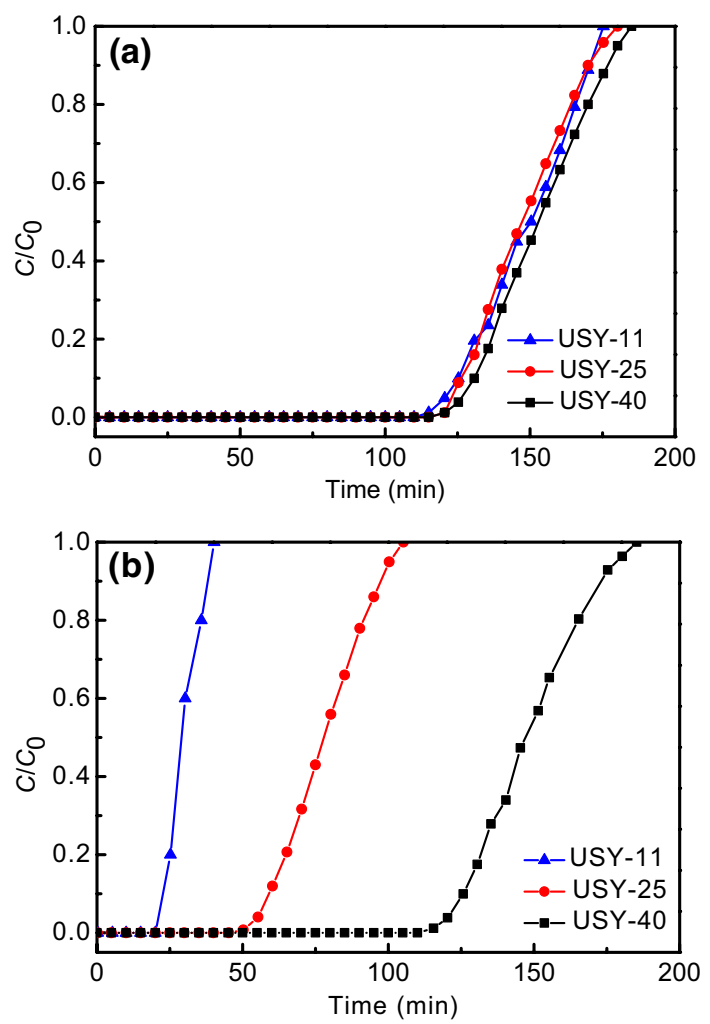

Fig. 3 Breakthrough curves of toluene at different relative humidities: a $\mathrm{RH}=0 \%$; b $\mathrm{RH}=50 \%$; initial concentration: $1500 \mathrm{mg} / \mathrm{m}^{3}$; feed flow rate: $450 \mathrm{~mL} / \mathrm{min}$; adsorption temperature: $25^{\circ} \mathrm{C}$

$\mathrm{Al}$ ratios. The USY with $\mathrm{Si} / \mathrm{Al}$ ratio of 40 presented great hydrophobicity. When the relative humidity was $50 \%$, the adsorption ratio of toluene reached $98.6 \%$. Therefore, USY $(\mathrm{Si} / \mathrm{Al}=40)$ is an excellent adsorbent with good adsorption performance and hydrophobicity.

\section{Effects of Adsorption Conditions}

The adsorption properties of toluene at different adsorption conditions are shown in Fig. 4. The breakthrough time decreased from $140 \mathrm{~min}$ to $80 \mathrm{~min}$, and the adsorbed amount decreased from 0.223 to $0.183 \mathrm{~g} / \mathrm{g}$ as the bed temperature increased from 15 to $35{ }^{\circ} \mathrm{C}$. These results indicated that increasing bed temperature negatively influenced toluene adsorption. This conclusion was consistent with that of a former study [32].

Feed flow rate also presented a significant influence on adsorption. The breakthrough time reduced from 265 to $85 \mathrm{~min}$ as feed flow rate increased from 200 to $700 \mathrm{~mL} / \mathrm{min}$. However, the adsorption capacity increased from 0.181 to $0.224 \mathrm{~g} / \mathrm{g}$. This result indicated that increasing feed flow rate enhanced the adsorption capacity of VOCs.

Besides feed flow rate, the initial concentration also influenced adsorption. The breakthrough time decreased
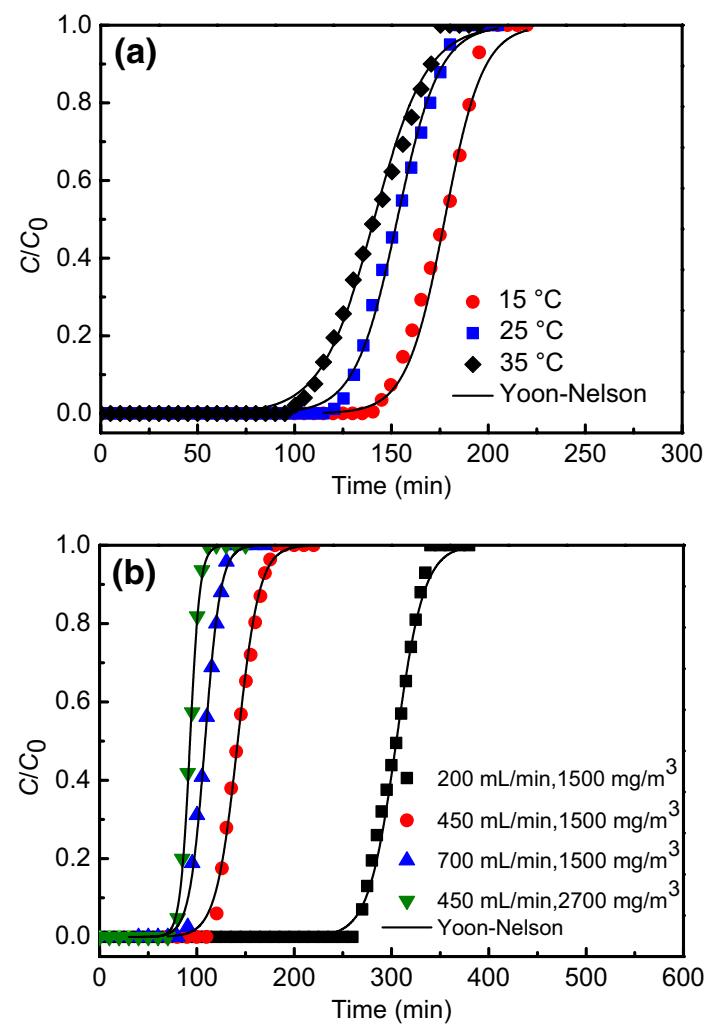

Fig. 4 Effects of operation conditions on adsorption: a initial concentration: $1500 \mathrm{mg} / \mathrm{m}^{3}$; feed flow rate: $450 \mathrm{~mL} / \mathrm{min}$; b adsorption temperature: $25^{\circ} \mathrm{C}$

from $115 \mathrm{~min}$ to $75 \mathrm{~min}$ with the increase in initial toluene concentration from 1500 to $2700 \mathrm{mg} / \mathrm{m}^{3}$. However, the amount of adsorbed toluene increased from 0.204 to $0.231 \mathrm{~g} / \mathrm{g}$, which was attributed to the enhanced driving force to diffusion.

Yoon-Nelson model can well fit the breakthrough curves of toluene. The length of mass transfer zone $\left(H_{\mathrm{MTZ}}\right)$ was estimated via the toluene breakthrough curves. The detailed fitting parameters of the Yoon-Nelson model and $H_{\mathrm{MTZ}}$ are presented in Table 2. A high rate constant $k$ was gained under low bed temperature, high feed flow rate, and high initial toluene concentration. However, the length of mass transfer zone increased with bed temperature and feed flow rate.

\section{Adsorption Kinetics}

The adsorption kinetic curves of toluene are shown in Fig. 5. During adsorption, the adsorbent bed underwent a stable state, breakthrough state, and saturation state successively. In the stable state, the mass transfer zone did not reach the boundary of the adsorbent bed. Toluene molecules were steadily adsorbed on USY, so the amount of toluene adsorbed linearly increased with time. Hence, it could be 
Table 2 Fitting parameters of the Yoon-Nelson model and $H_{\mathrm{MTZ}}$

\begin{tabular}{|c|c|c|c|c|c|c|}
\hline \multicolumn{3}{|c|}{ Adsorption conditions } & \multirow[t]{2}{*}{$q_{\mathrm{e}}(\mathrm{g} / \mathrm{g})$} & \multirow[t]{2}{*}{$k$} & \multirow[t]{2}{*}{$R^{2}$} & \multirow[t]{2}{*}{$H_{\mathrm{MTZ}}(\mathrm{cm})$} \\
\hline $\begin{array}{l}\text { Bed tempera- } \\
\text { ture }\left({ }^{\circ} \mathrm{C}\right)\end{array}$ & $\begin{array}{l}\text { Feed flow rate } \\
(\mathrm{mL} / \mathrm{min})\end{array}$ & $\begin{array}{l}\text { Initial toluene concen- } \\
\text { tration }\left(\mathrm{mg} / \mathrm{m}^{3}\right)\end{array}$ & & & & \\
\hline 15 & 450 & 1500 & 0.223 & 0.102 & 0.991 & 0.825 \\
\hline 25 & 450 & 1500 & 0.204 & 0.092 & 0.996 & 1.019 \\
\hline 35 & 450 & 1500 & 0.183 & 0.073 & 0.994 & 1.302 \\
\hline 25 & 200 & 1500 & 0.181 & 0.070 & 0.992 & 0.713 \\
\hline 25 & 700 & 1500 & 0.224 & 0.126 & 0.997 & 1.049 \\
\hline 25 & 450 & 2700 & 0.231 & 0.197 & 0.998 & 0.813 \\
\hline
\end{tabular}

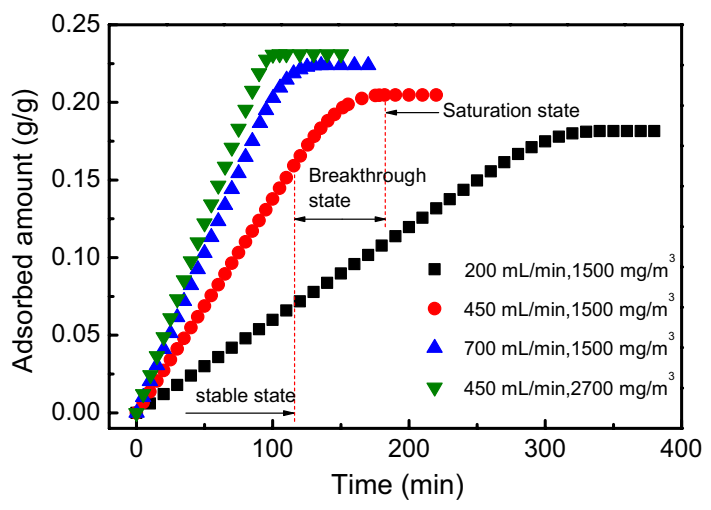

Fig. 5 Adsorption kinetic curves of toluene on USY at various inlet conditions

fitted by the pseudo-zero-order model. Table 3 shows the detailed fitting parameters. Increasing the feed flow rate or initial toluene concentration elevated the adsorption rate.

The breakthrough state was fitted by the pseudo-firstorder model, also shown in Table 3. Increasing the feed flow rate or initial concentration can also enhance the adsorption rate.

\section{Adsorption Isotherms and Isosteric Heat}

The adsorption isotherms were obtained by adsorption experimental instruments (shown in Fig. 1) via kinetic adsorption. The toluene adsorbed amount increased with partial pressure of toluene, shown in Fig. 6a. The adsorption isotherm was simulated by different adsorption models.
The detailed fitting parameters are summarized in Table 4 . The order of $R^{2}$ of various adsorption isotherm models was Langmuir-Freundlich > Langmuir $>$ Freundlich. This result indicated that the adsorption surface of USY was heterogeneous, containing both homogeneous and multilayer adsorption.

The isosteric heat of toluene adsorption was calculated from adsorption isotherms by using the Clausius-Clapeyron equation, shown in Fig. 6b. The isosteric heat of toluene adsorption on USY was in the range of $54.3-69.8 \mathrm{~kJ} / \mathrm{mol}$, which suggested physical adsorption. The isosteric heat curve increased with rising adsorbed amount of toluene, which may be attributed to the interaction between toluene molecules [33].

\section{Comparison of Various Desorption Methods}

Figure 7 shows a comparison of different desorption methods. By use of VSA, the lowest desorption rate (12.6\%) was obtained within 40 min because vacuum could hardly break the strong interaction between USY and toluene molecules. The desorption rate reached $80.9 \%$ within 40 min by TSA, which was attributed to the inhibition of the dynamic adsorption of toluene due to increasing adsorbent bed temperature. Thus, the adsorbed toluene molecules were removed by constant purge gas. However, TVSA presented the highest desorption rate $(90.6 \%)$ and shortest removal time (10 min) possibly because vacuum weakened the interaction between toluene molecules and USY. Therefore, in comparison with TSA, toluene molecules were easily released. These results suggested that TVSA is a promising method for the removal

Table 3 Fitting parameters of pseudo-zero-order model and pseudo-first-order model

\begin{tabular}{|c|c|c|c|c|c|c|c|c|}
\hline \multirow[t]{2}{*}{ Model parameters } & \multicolumn{4}{|c|}{ Pseudo-zero-order model } & \multicolumn{4}{|c|}{ Pseudo-first-order model } \\
\hline & $k_{0}\left(10^{-4} \mathrm{~g} / \mathrm{min}\right)$ & $t_{0}(\min )$ & $q_{0}(\mathrm{~g} / \mathrm{g})$ & $R_{0}^{2}$ & $\overline{k_{1}\left(\min ^{-1}\right)}$ & $t_{1}(\min )$ & $q_{\mathrm{e}}(\mathrm{g} / \mathrm{g})$ & $R_{1}^{2}$ \\
\hline $200 \mathrm{~mL} / \mathrm{min}, 1500 \mathrm{mg} / \mathrm{m}^{3}$ & 6 & 260 & 0.1556 & 0.9996 & 0.0208 & 380 & 0.1814 & 0.9278 \\
\hline $450 \mathrm{~mL} / \mathrm{min}, 1500 \mathrm{mg} / \mathrm{m}^{3}$ & 14 & 110 & 0.1515 & 0.9998 & 0.0238 & 220 & 0.2047 & 0.9675 \\
\hline $700 \mathrm{~mL} / \mathrm{min}, 1500 \mathrm{mg} / \mathrm{m}^{3}$ & 21 & 85 & 0.1750 & 0.9995 & 0.0365 & 170 & 0.2239 & 0.9635 \\
\hline $450 \mathrm{~mL} / \mathrm{min}, 2700 \mathrm{mg} / \mathrm{m}^{3}$ & 24 & 75 & 0.1832 & 0.9997 & 0.0415 & 150 & 0.2312 & 0.9942 \\
\hline
\end{tabular}



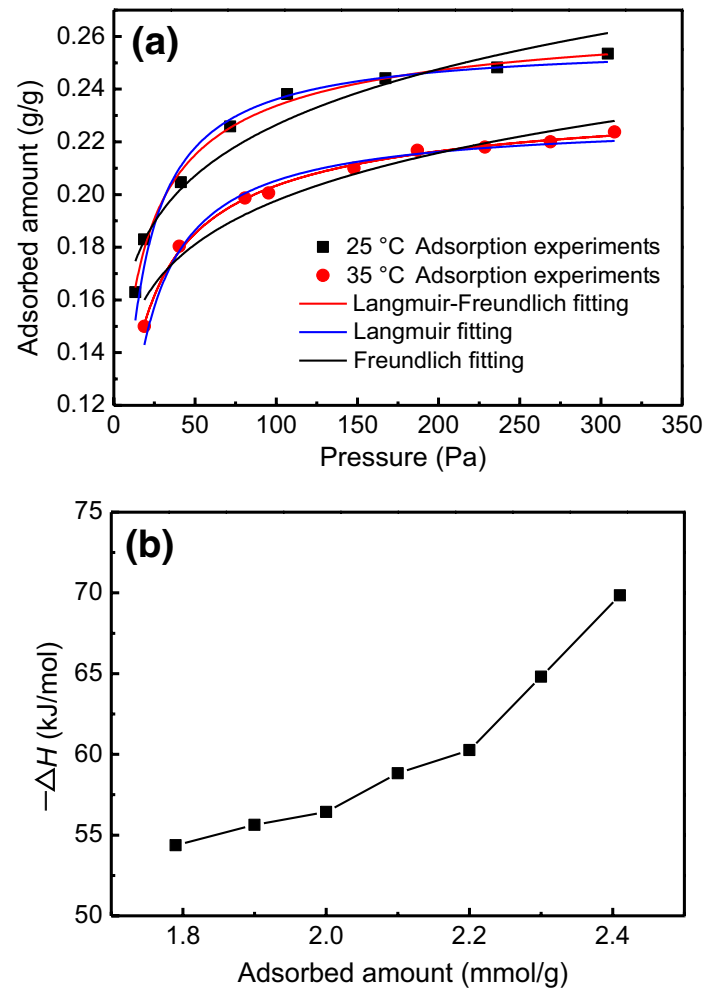

Fig. 6 Adsorption isotherm simulation (a) and isosteric heat of toluene (b)

of heavy VOCs, which could enhance the desorption rate and reduce the desorption time.

\section{Desorption Activation Energy}

To further investigate the mechanism of TVSA, the desorption activation energy of toluene at different pressure values was calculated via TPD. In this case, desorption was assumed to follow Arrhenius-like behavior and first-order kinetics. The activation energy was estimated by the modified Polanyi-Wigner equation. Figure $8 \mathrm{a}, \mathrm{b}$ shows the toluene TPD spectra at heating rates from 3 to $15 \mathrm{~K} / \mathrm{min}$. The intensity of the TPD spectra and temperature corresponding to desorption peak increased with the heating rate. The calculated desorption activation energy results are also depicted in Fig. 8c, d. The desorption activation energy at atmosphere pressure was $71.217 \mathrm{~kJ} / \mathrm{mol}$, which was higher than the isosteric heat of toluene adsorption. However, the desorption activation energy at $10 \mathrm{kPa}$ was only $55.970 \mathrm{~kJ} / \mathrm{mol}$, which was $21 \%$ lower than that at atmosphere pressure. Vacuum clearly reduced the desorption activation energy. Therefore, TVSA presented better desorption performance than TSA.

\section{Optimization of Desorption Conditions}

To provide operational guidance for industry, the desorption conditions of TVSA were optimized. Vacuum pressure, bed temperature, and purge gas flow rate are important parameters in desorption. Low pressure is advantageous for desorption [10]. Therefore, the desorption process should be conducted at the lowest pressure permitted by the VOC purification plant. Considering the equipment factors, $10 \mathrm{kPa}$ was set as the desorption pressure.

The relationship between desorption rate and temperature is shown in Fig. 9. The desorption rate sharply increased within $5 \mathrm{~min}$ and remained stable after $10 \mathrm{~min}$. A high desorption rate was obtained at high desorption temperatures. However, the desorption rates at $120^{\circ} \mathrm{C}$ and $140{ }^{\circ} \mathrm{C}$ were similar to each other ( $90.6 \%$ and $91.7 \%$, respectively). Therefore, considering energy consumption, desorption

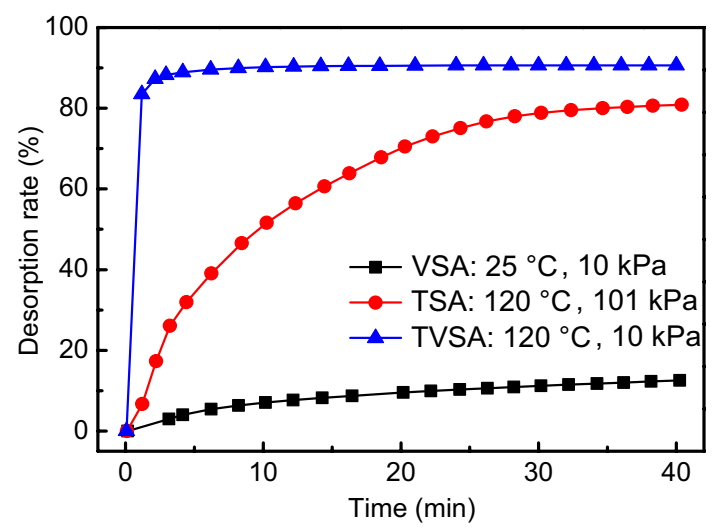

Fig. 7 Comparison of different desorption methods: purge gas flow rate: $200 \mathrm{~mL} /\left(\mathrm{min} \cdot \mathrm{g}_{\text {adsorbent }}\right)$; toluene amount adsorbed: $0.204 \mathrm{~g} / \mathrm{g}$
Table 4 Fitting parameters of different adsorption isotherms

\begin{tabular}{lllllll}
\hline $\begin{array}{l}\text { Bed tempera- } \\
\text { ture }\left({ }^{\circ} \mathrm{C}\right)\end{array}$ & Fitting models & $q_{\mathrm{m}}(\mathrm{g} / \mathrm{g})$ & $k$ & $A$ & $1 / n$ & $R^{2}$ \\
\hline 25 & Langmuir & 0.2579 & 0.1085 & - & - & 0.9827 \\
25 & Freundlich & - & - & 0.1252 & 0.1287 & 0.9386 \\
25 & Langmuir-Freundlich & 0.2742 & 0.2688 & - & 0.6656 & 0.9916 \\
35 & Langmuir & 0.2284 & 0.0889 & - & - & 0.9888 \\
35 & Freundlich & - & - & 0.1103 & 0.1266 & 0.9436 \\
35 & Langmuir-Freundlich & 0.2413 & 0.2132 & - & 0.7005 & 0.9960 \\
\hline
\end{tabular}



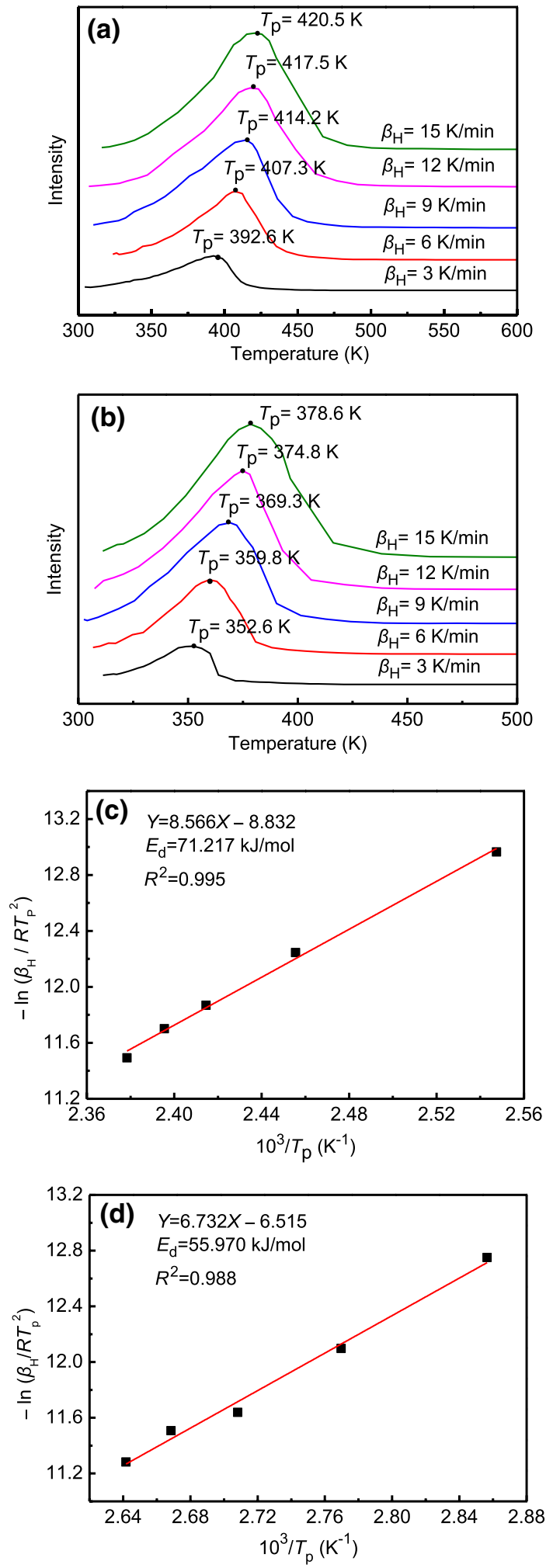

Fig. 8 TPD curves and desorption activation energy of toluene at different desorption pressures: a, c $101.3 \mathrm{kPa} ; \mathbf{b}, \mathbf{d} 10 \mathrm{kPa}$

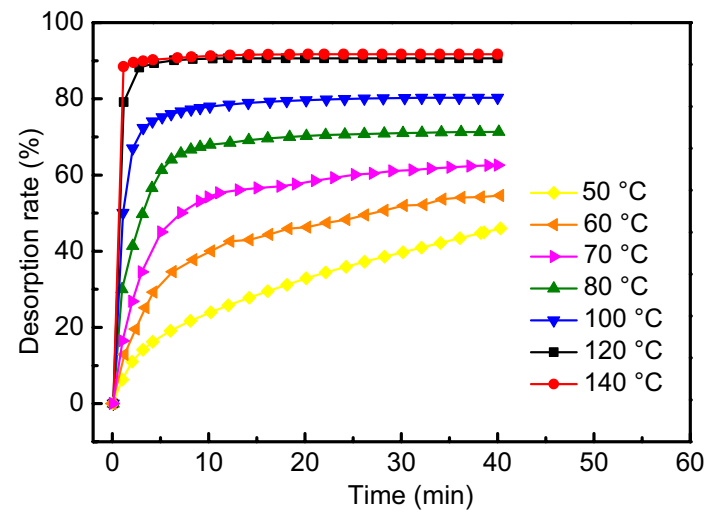

Fig. 9 Effect of temperature on desorption (Purge gas flow rate: $200 \mathrm{~mL} /\left(\mathrm{min} \cdot \mathrm{g}_{\text {adsorbents }}\right)$; toluene amount adsorbed: $0.204 \mathrm{~g} / \mathrm{g}$ )

temperature and desorption time were set at $120^{\circ} \mathrm{C}$ and 10 min, respectively.

Figure 10 shows how the purge gas flow rate influences the desorption rate. A similar conclusion was obtained, in which increasing purge gas flow rate was found to be beneficial for desorption. The desorption rates were $86.7 \%$, $90.6 \%$, and $91.1 \%$ at the purge gas flow rates of $100 \mathrm{~mL} /$

(a)

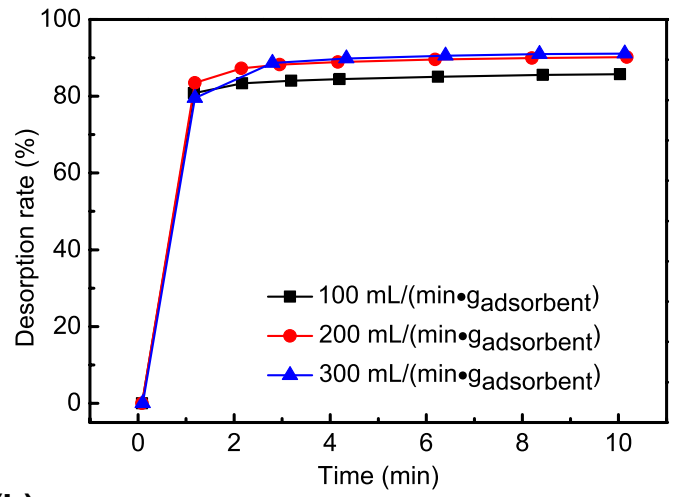

(b)

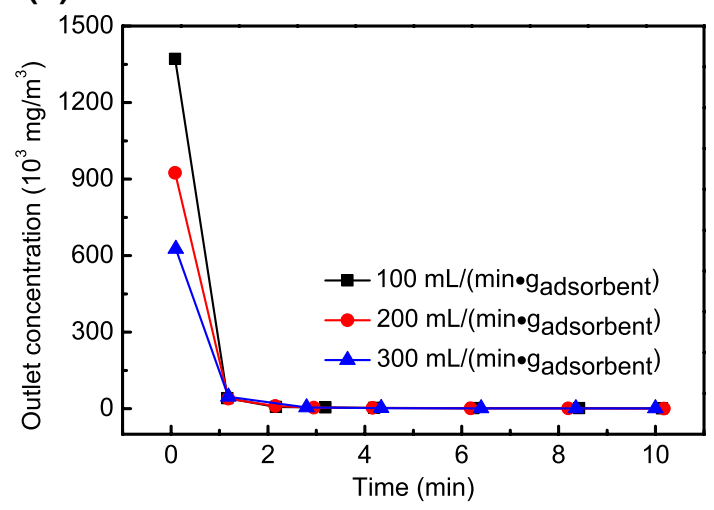

Fig. 10 Effect of purge gas flow rate on desorption (Desorption temperature: $120^{\circ} \mathrm{C}$; toluene amount adsorbed: $0.204 \mathrm{~g} / \mathrm{g}$ ) 


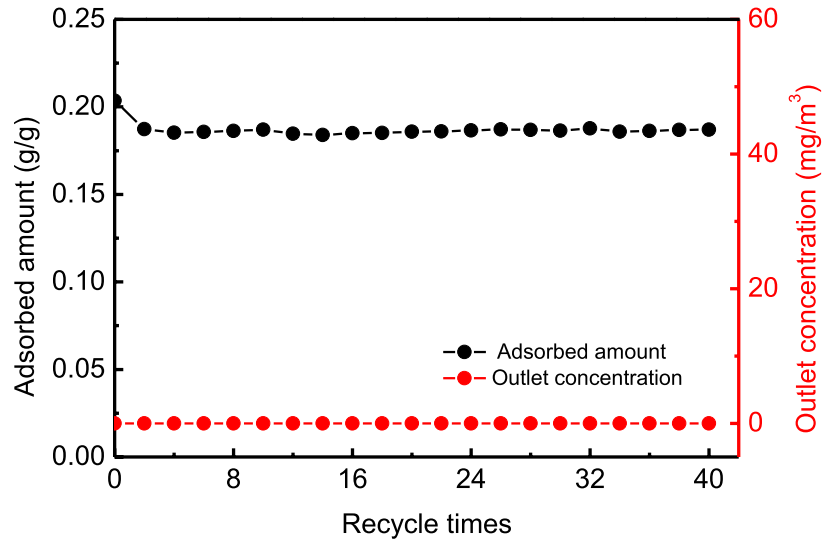

Fig. 11 Adsorption performance of long-term cyclic utilization (Adsorption temperature: $25{ }^{\circ} \mathrm{C}$; initial concentration: $1500 \mathrm{mg} / \mathrm{m}^{3}$; feed flow rate: $450 \mathrm{~mL} / \mathrm{min}$; desorption temperature: $120{ }^{\circ} \mathrm{C}$; purge gas flow rate: $200 \mathrm{~mL} /\left(\mathrm{min} \cdot \mathrm{g}_{\text {adsorbent }}\right)$; desorption pressure: $10 \mathrm{kPa}$; and adsorbent mass: $0.5 \mathrm{~g}$ )

$\left(\mathrm{min} \cdot \mathrm{g}_{\text {adsorbent }}\right), 200 \mathrm{~mL} /\left(\mathrm{min} \cdot \mathrm{g}_{\text {adsorbent }}\right)$, and $300 \mathrm{~mL} /$ (min $\left.\cdot g_{\text {adsorbent }}\right)$, respectively.

The initial outlet concentration of toluene was high and then sharply fell. After $3 \mathrm{~min}$, the concentration of toluene gradually approached zero. Given that the initial outlet concentration was high, most of toluene was recycled by condensing. However, the initial outlet concentration of toluene sharply decreased with increasing purge gas flow rate. Low concentrations of toluene are disadvantageous for condensation recovery. Thus, considering both desorption rate and outlet concentration, the purge gas flow rate was determined as $200 \mathrm{~mL} /\left(\mathrm{min} \cdot \mathrm{g}_{\text {adsorbent }}\right)$.

\section{Long-Term Cyclic Utilization by TVSA}

Stability is one of the most important properties in industrial applications. Hence, after optimizing the desorption conditions, long-term cyclic utilization experiments were carried out (Fig. 11). In the second recycle, the adsorbed amount decreased from 0.2 to $0.18 \mathrm{~g} / \mathrm{g}$, which was ascribed to the irreversible adsorption of toluene [34]. However, the adsorbed amount of toluene was maintained at $0.18 \mathrm{~g} / \mathrm{g}$ during long-term recycling. The outlet concentration of toluene before breakthrough was detected as $0 \mathrm{mg} / \mathrm{m}^{3}$, which was lower than the national emission standard $\left(15 \mathrm{mg} / \mathrm{m}^{3}\right.$ from GB31571-2015). These results suggested that USY as adsorbent presents excellent adsorption stability.

\section{Conclusions}

USY is an excellent adsorbent for VOCs, which has large adsorption capacity and good hydrophobicity. Lowering the bed temperature and increasing the feed flow rate and initial concentration are proven to be beneficial for VOC adsorption. The Yoon-Nelson model could fit the breakthrough curves of VOCs. The length of mass transfer zone calculated from the breakthrough curves increased with rising adsorbent bed temperature and feed flow rate. The adsorbed amount of toluene at stable adsorption state and breakthrough state was well fitted by the pseudo-zero-order and pseudo-first-order models, respectively. The adsorption isotherm of toluene on USY was fitted by the Langmuir-Freundlich model. The adsorption isosteric heat of toluene was in the range of $54.3-69.8 \mathrm{~kJ} / \mathrm{mol}$, indicating physical adsorption. TVSA method exhibited superior desorption performance compared with TSA and VSA methods. The desorption activation energy calculated by TPD was $71.217 \mathrm{~kJ} / \mathrm{mol}$ at the desorption pressure of $101.3 \mathrm{kPa}$ and $55.970 \mathrm{~kJ} / \mathrm{mol}$ at the desorption pressure of $10 \mathrm{kPa}$. The optimal desorption conditions at laboratory scale were $10 \mathrm{kPa}$ of desorption pressure, $120{ }^{\circ} \mathrm{C}$ of desorption temperature and $200 \mathrm{~mL} /\left(\mathrm{min} \cdot \mathrm{g}_{\text {adsorbent }}^{-1}\right)$ of purge gas flow rate. At these conditions, the desorption rate could reach $90.6 \%$ within $10 \mathrm{~min}$. The long-term cyclic utilization results suggested that the adsorbed amount of toluene was stabilized at $0.18 \mathrm{~g} / \mathrm{g}$. Therefore, TVSA using USY as adsorbent is a promising way for the removal of heavy VOCs.

OpenAccess This article is distributed under the terms of the Creative Commons Attribution 4.0 International License (http://creativecommons.org/licenses/by/4.0/), which permits unrestricted use, distribution, and reproduction in any medium, provided you give appropriate credit to the original author(s) and the source, provide a link to the Creative Commons license, and indicate if changes were made.

\section{References}

1. Zhang L, Peng Y, Zhang J et al (2016) Adsorptive and catalytic properties in the removal of volatile organic compounds over zeolite-based materials. Chin J Catal 37(6):800-809

2. Zhou H, Tao F, Liu Q et al (2017) Microporous polyamide membranes for molecular sieving of nitrogen from volatile organic compounds. Angew Chem Int Ed 129(21):5755-5759

3. Zheng C, Shen J, Zhang Y et al (2017) Quantitative assessment of industrial VOC emissions in China: historical trend, spatial distribution, uncertainties, and projection. Atmos Environ 150:116-125

4. Aziz A, Kim KS (2017) Synergistic effect of UV pretreated FeZSM5 catalysts for heterogeneous catalytic complete oxidation of VOC: a technology development for sustainable use. J Hazard Mater 340:351-359

5. Hu L, Cheng W, Zhang W et al (2016) Monolithic bamboo-based activated carbons for dynamic adsorption of toluene. J Porous Mater 24(2):1-9

6. Seida Y, Suzuki T (2017) Adsorption properties of stearyl acrylate gel for VOC observed by QCM-A. Macromol Symp 372(1):132-139

7. Romero-Anaya AJ, Lillo-Ródenas MA, Linares-Solano A (2015) Factors governing the adsorption of ethanol on spherical activated carbons. Carbon 83:240-249 
8. Biard PF, Coudon A, Couvert A et al (2016) A simple and timesaving method for the mass-transfer assessment of solvents used in physical absorption. Chem Eng J 290(2):302-311

9. Takeuchi M, Hidaka M, Anpo M et al (2012) Efficient removal of toluene and benzene in gas phase by the $\mathrm{TiO}_{2} / \mathrm{Y}$-zeolite hybrid photocatalyst. J Hazard Mater s237-238(7):133-139

10. Hou J, Li Y, Mao M et al (2015) Full solar spectrum light driven thermocatalysis with extremely high efficiency on nanostructured Ce ion substituted OMS-2 catalyst for VOCs purification. Nanoscale 7(6):2633-2640

11. Wu Z, Zhu Z, Hao X et al (2018) Enhanced oxidation of naphthalene using plasma activation of $\mathrm{TiO}_{2} /$ diatomite catalyst. J Hazard Mater 347:48-57

12. Khoramfar S, Jones KD, Boswell J et al (2018) Evaluation of a sequential biotrickling-biofiltration unit for removal of VOCs from the headspace of crude oil storage tanks. J Chem Technol Biotechnol 93(6):1778-1789

13. Sui H, Liu H, An P et al (2017) Application of silica gel in removing high concentrations toluene vapor by adsorption and desorption process. J Taiwan Inst Chem Eng 74:218-224

14. Baek SW, Kim JR, Ihm SK (2004) Design of dual functional adsorbent/catalyst system for the control of VOC's by using metalloaded hydrophobic Y-zeolites. Catal Today s93-95:575-581

15. Serra RM, Miró EE, Bolcatto P et al (2012) Experimental and theoretical studies about the adsorption of toluene on ZSM-5 and mordenite zeolites modified with Cs. Microporous Mesoporous Mater 147(1):17-29

16. Swetha G, Gopi T, Shekar SC et al (2017) Combination of adsorption followed by ozone oxidation with pressure swing adsorption technology for the removal of VOCs from contaminated air streams. Chem Eng Res Des 117:725-732

17. Wakasugi R, Kodama A, Goto M et al (2004) Recovery of volatile organic compounds as condensate by pressure swing adsorption with enriching reflux. J Chem Eng Jpn 37(2):374-377

18. Gales L, Mendes A, Costa C (2003) Recovery of acetone, ethyl acetate and ethanol by thermal pressure swing adsorption. Chem Eng Sci 58(23-24):5279-5289

19. Intyre JAM, And CEH, Ritter JA (2002) High enrichment and recovery of dilute hydrocarbons by dual-reflux pressure-swing adsorption. Ind Eng Chem Res 41(14):3499-3504

20. Sui H, An P, Li X et al (2017) Removal and recovery of o-xylene by silica gel using vacuum swing adsorption. Chem Eng J 316:232-242

21. Pak SH, Jeon YW (2017) Effect of vacuum regeneration of activated carbon on volatile organic compound adsorption. Environ Eng Res 22(2):169-174
22. Hu L, Peng Y, Wu F et al (2017) Tubular activated carbons made from cotton stalk for dynamic adsorption of airborne toluene. $\mathrm{J}$ Taiwan Inst Chemical Eng 80:399-405

23. Lemus J, Martin-Martinez M, Palomar J et al (2012) Removal of chlorinated organic volatile compounds by gas phase adsorption with activated carbon. Chem Eng J 211:246-254

24. Lee MG, Lee SW, Lee SH (2006) Comparison of vapor adsorption characteristics of acetone and toluene based on polarity in activated carbon fixed-bed reactor. Korean J Chem Eng 23(5):773-778

25. Kundu S, Gupta AK (2006) Arsenic adsorption onto iron oxidecoated cement (IOCC): Regression analysis of equilibrium data with several isotherm models and their optimization. Chem Eng J 122(1-2):93-106

26. Freundlich HMF (2006) Over the adsorption in solution. J Phys Chem 57:385-471

27. Azizian S, Haerifar M, Basiri-Parsa J et al (2007) Extended geometric method: a simple approach to derive adsorption rate constants of Langmuir-Freundlich kinetics. Chemosphere 68(11):2040-2046

28. Young DM, Crowell AD, Rice SA (1962) Physical adsorption of gases. Butterworths 235(1):1214-1225

29. Zhao Z, Sha W, Yan Y et al (2015) Competitive adsorption and selectivity of benzene and water vapor on the microporous metal organic frameworks (HKUST-1). Chem Eng J 259:79-89

30. Wang S, Liang Z, Chao L et al (2014) Enhanced adsorption and desorption of VOCs vapor on novel micro-mesoporous polymeric adsorbents. J Colloid Interface Sci 428:185-190

31. Sharma A, Lee BK (2017) A novel nanocomposite of $\mathrm{Ca}(\mathrm{OH})_{2^{-}}$ incorporated zeolite as an additive to reduce atmospheric emissions of PM and VOCs during asphalt production. Environ Sci Nano 4(3):613-624

32. Fang Q, Zhu LZ, Yang K (2009) Adsorption behaviors of volatile organic compounds (VOCs) on porous clay heterostructures (PCH). J Hazard Mater 170(1):7-12

33. Lee CK, Chen HC, Liu SS et al (2010) Effects of acid washing treatment on the adsorption equilibrium of volatile organic compounds on titanate nanotubes. J Taiwan Inst Chem Eng 41(3):373-380

34. Zhu J, Li YH, Xu L et al (2018) Removal of toluene from waste gas by adsorption-desorption process using corncob-based activated carbons as adsorbents. Ecotoxical Environ Saf 165:115-125 